\title{
Gaps in the System
}

\author{
SHERRIE REYNOLDS \\ Texas Christian University (USA)
}

Deborah Seltzer-Kelly et al, created a most interesting symposium which was the basis for the Feature Article in this issue, (Re)imagining teacher preparation for conjoint democratic inquiry in complex classroom ecologies. True to the heart of complexity and post-modern thought, the article has selected a series of perspectives that, while compatible, cannot really be resolved into a single meta-narrative. I find that a very Batesonian approach in that Gregory Bateson (2000) believed so strongly in what he called gappiness. Complex systems and complex ideas, by their nature, cannot be easily described except metaphorically and when we try to get too specific, when we try to eliminate the messiness, we flatten the system. Metaphor, for Bateson and perhaps for this SIG, is the heart of description for complex ideas and, like Bateson, we should perhaps refuse to explain our metaphors.

There were two threads in the paper to which I would like to respond: the fault lines in systems related to schooling and some places we might look for remedy.

\section{Cracks in the system}

The authors have noticed fault lines in the system made clear, as fault lines often are, when stresses are applied to it.

- Student fault lines appear when the increasing diversity of students is not matched by changes in the system. More and more students are not at the table and school has not learned to make a bigger table, but has simply blamed the students for being unable to find their place.

- Teacher fault lines appear as teachers are unprepared for dealing with diverse and differently abled students and end up blaming the students or aligning themselves with a social system that alienates the students. 
- Systemic fault lines occur in the disjunction between culture and school. Many years ago Lev Vygotsky (1986) noticed the gap between what he termed academic knowledge and everyday knowledge. More recently, in Schwartz and Ogilivy (1979) mapped some of the intellectual foundational change that we loosely refer to as post-modernism, but those ideas and ways of thinking have not yet arrived in schools. This fault reverberates through the lives of teachers and students as they perceive the disjuncture and find themselves powerless except to express it through dropping out, hitting back or learning to play the game. The first two, of course, are academic suicide, but the latter, as was pointed out in the papers today, is more like the gradual dulling that constitutes a death of a thousand cuts. The notion that one can ignore large segments of the population, ignore change, and continue to insist that everyone find a way to fit into a system that is disjunctive with the larger culture persists in spite of its obvious and devastating failure.

- In one way or another, all of the authors point to the failure to recognize the complexity of American education as a system, including the failure of research that has misled us into seeking individualistic and linear solutions. The failure to envision school as a system contributed to the inability of schools to escape their hegemony and create space for genuine relationship, valuing diversity of background, experience, talent, and ways of knowing and to assist students in imagining and finding their destiny rather than sorting them "like candidates placed on a waiting list" in preparation for adult life.

\section{Re-imagining Education}

The second thread that captured me was the various ways that the authors re-imagine schooling as a potential for re-invigorating democracy. They assure us that true democracy requires diversity of thought and that encounters with multiple perspectives enables one to reconstruct their own ideas. These authors ask us to move schooling away from dulling compliance and into the development of student's deepest sense of vocation.

The authors suggest that diversity is not a problem, but an opportunity and perhaps a necessity. Bateson (1979) noted that an emphasis on difference leads to patterns and the understanding of patterns is what allows us to decenter humans and see the necessary unity of all of nature.

I suggest that systems theory, and perhaps family systems theory in particular, have something to offer here. Psychologists years ago noticed that when one person, usually a child, was brought in for therapy, as the child began to recover someone else in the family began to develop problems. Often it was as if the symptoms ran through the children, then usually to the wife. We determined that one can not deal with someone who is embedded in a system of interactions as if he/she were an individual. The family has to be dealt with as a whole, and psychologists began to see families and look at family interactions rather than placing the problem in the individual. That is, we look for 
patterns of interaction and communication. As our authors suggested here today, individuals in communication with each other, construct values, symbols and constraints. We know who we are in relationship and that is true at the level of dyads and larger systems.

We know that systems cannot be changed from outside the system and this is part of the challenge. We have to become spiritual in the Batesonian sense where we develop a sensitivity to the system, and the systems of feedback that sustain it rather than operating as though education is a machine that has developed a defect in one of its parts. It is difficult to teach someone how to lean into a system and listen for what it is telling us, but perhaps those are the kinds of experiences we need to help teachers develop. Teachers often make decisions, like most other humans, from a kind of intuitive-imaginative intelligence. Until recently we did not recognize this mode of thought and it is, as our authors have said, where the hope for schooling may reside. Teachers and students need experiences of this contact with the spiritual, or the system, or whatever you choose to call it and to refine our ability to listen and respond. We cannot fully understand a recursive human system through cognition alone, we must also create a perceptual, aesthetic, sacred space for its interpretation and for thinking about ecological wholes.

Lastly, I was reminded as the authors spoke, of Humberto Maturana and Fransisco Varela's (1980) notion of structural coupling and Bateson's (1989) idea of time-binding. As Yvonna Lincoln once noted, we treat as natural what is only historical. We also treat as causal what is only historical. It might be beneficial to think about systems as nonlinear, multi-level oscillating patterns of communication that occur and have occurred in time. We must learn to see the patterns of relations that make up schooling, to understand that we and the systems in which we participate are a single field of reciprocal interaction in which we modify each other.

We cannot ignore the necessity of diversity, imagination, spiritual connection and relationship pointed out in these papers. We do so at the peril of becoming the next failed country and failed set of ideas. Jean Piaget said that the mark of mature thought is that we can allow an idea to die so that we, as a species, don't have to. Let's hope we can find enough mature thinkers that we can all survive until we make it to the other side of this culture chasm.

\section{References}

Bateson, Gregory 2000 [1972]. Steps to an ecology of mind. Chicago: The University of Chicago Press.

Bateson, G. (1979). Mind and nature. A necessary unity. Toronto: Bantam Books

Bateson, Gregory; Bateson, Mary Catherine 1987. Angels fear: Towards an epistemology of the sacred. New York: Macmillan Publishing Co.

Maturana, H. \& Varela, F. 1980 [1973]. Autopoesis and cognition: The realization of the living. Boston Studies in the Philosophy of Science, 42. Boston: Reidel.

Schwartz, P. and J. Ogilvy 1979. The emergent paradigm: Changing patterns of thought and belief. VALS Report No. 7. Menlo Park, CA: Values and Lifestyles Program, 1979.

Vygotsky, Lev 1986. Thought and language. MA: The MIT Press. 


\section{About the Author}

Sherrie Reynolds is a professor of Educational Psychology and Curriculum Studies at Texas Christian University in Fort Worth, Texas. Her research has focused on change in a broad sense, and conceptual change in relation to the New Sciences of Chaos and Complexity in particular. Her most recent books are Higher Education Reconceived: A Geography of Change (2010, TCU Press) and The Arms of God: Sisters of St. Mary of Namur, Western Province (in press, Wipf \& Stock).

(C) Copyright 2011. The author, Sherrie Reynolds, assigns to the University of Alberta and other educational and non-profit institutions a non-exclusive license to use this document for personal use and in courses of instruction provided that the article is used in full and this copyright statement is reproduced. The author also grants a non-exclusive license to the University of Alberta to publish this document in full on the World Wide Web, and for the document to be published on mirrors on the World Wide Web. Any other usage is prohibited without the express permission of the authors. 